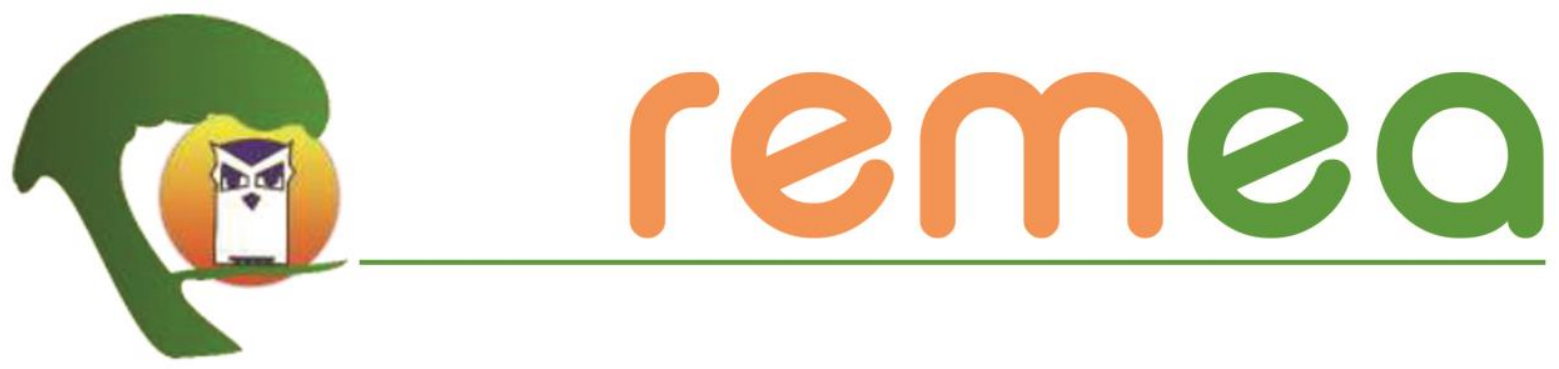

\title{
A problemática das políticas públicas ambientais no Brasil
}

\author{
Arícia Fernandes Macedo Castelo ${ }^{1}$ \\ Universidade de Fortaleza - UNIFOR \\ ORCID: https://orcid.org/0000-0002-7915-5886 \\ Fábio Freitas Schilling Marquesan ${ }^{2}$ \\ Universidade de Fortaleza - UNIFOR \\ ORCID: https://orcid.org/0000-0002-2456-4914 \\ Joselito Brilhante Silva ${ }^{3}$ \\ Instituto Federal de Educação, Ciência e Tecnologia do Ceará - IFCE \\ ORCID: https://orcid.org/0000-0001-6856-7562
}

Resumo: As políticas públicas ambientais envolvem um conjunto de questões complexas, inovadoras e duradouras de ação coletiva que impactam sobre a sociedade e o meio ambiente. As leis, regulamentos, agências públicas e mecanismos participativos multiplicam a dificuldade do seu enquadramento institucional e a resolução dos problemas a que estão vinculados. Mesmo com o aprimoramento da legislação ambiental, a complexidade envolta tem gerado conflitos e dificuldades sociais. $O$ objetivo foi analisar a influência sobre o contexto local e compreensão dos aspectos críticos das políticas públicas ambientais no Brasil, possibilitando uma reflexão sobre desafios, possibilidades e meios usados para um desenvolvimento sustentável. Concluiu-se que a gestão das políticas públicas pode contribuir para mitigação dos problemas ambientais como pode abrir precedentes capazes de gerar e agravar conflitos sociais.

Palavras-chave: Políticas públicas, Meio ambiente, Legislação ambiental.

\section{El problema de las políticas públicas ambientales en Brasil}

Resumen: Las políticas públicas ambientales involucran un conjunto de temas de acción colectiva complejos, innovadores y duraderos que impactan a la sociedad y al medio ambiente. Leyes, reglamentos, agencias públicas y mecanismos participativos multiplican la dificultad de su institucionalidad y la resolución de los problemas a los que están vinculados. Incluso con la mejora de la legislación ambiental, la complejidad involucrada ha generado conflictos y dificultades sociales. El objetivo fue analizar la influencia en el contexto

\footnotetext{
${ }^{1}$ Doutoranda do Programa de Pós-Graduação em Administração de Empresas da Universidade de Fortaleza UNIFOR E-mail: aricia castelo@hotmail.com

${ }^{2}$ Professor Adjunto do Programa de Pós-Graduação em Administração de Empresas da Universidade de Fortaleza - UNIFOR E-mail: marquesan@unifor.br

${ }^{3}$ Professor Efetivo do Instituto Federal de Educação, Ciência e Tecnologia do Ceará - IFCE E-mail: joselito@ifce.edu.br
} 
local y la comprensión de los aspectos críticos de las políticas públicas ambientales en Brasil, permitiendo una reflexión sobre los desafíos, posibilidades y medios utilizados para el desarrollo sostenible. Se concluyó que la gestión de políticas públicas puede contribuir a la mitigación de los problemas ambientales ya que puede sentar precedentes capaces de generar y agravar conflictos sociales.

Palabras clave: Políticas públicas, Medio ambiente, Legislación ambiental.

\title{
The problem of public environmental policies in Brazil
}

\begin{abstract}
The public environmental policies involve a set of complex, innovative and lasting collective action issues that impact on society and the environment. Laws, regulations, public agencies, and participatory mechanisms multiply the difficulty of their institutional framework and the resolution of the problems to which they are linked. Even with the improvement of environmental legislation, the complexity involved has generated conflicts and social difficulties. The objective was to analyze the influence on the local context and understanding of the critical aspects of public environmental policies in Brazil, enabling a reflection on the challenges, possibilities and means used for sustainable development. It was concluded that the management of public policies can contribute to the mitigation of environmental problems as it can set precedents capable of generating and aggravating social conflicts.
\end{abstract}

Keywords: Public policies, Environment, Environmental legislation.

\section{Introdução}

Desde meados dos anos 1960, aproximadamente, o mundo assumiu a preservação dos recursos naturais como uma preocupação na qual cada país deve ter sua quota de responsabilidade. A necessidade de proteção ambiental veio do reconhecimento de que a degradação do meio ambiente tem como consequência a degradação e o sofrimento do próprio ser humano. Além, é claro, do avanço de toda sorte de conflitos ambientais.

O agir administrativo do poder público sobre o meio ambiente volta-se para conservação e a proteção do meio ambiente, com o intuito de evitar consequências nefastas aos interesses da sociedade, ao meio ambiente e à qualidade de vida do ser humano. Um dos principais instrumentos utilizados pelo poder público para intervir na sociedade são as políticas públicas direcionadas à garantia da consecução das necessidades ambientais, combinando os interesses políticos e o conhecimento técnico e respeitando os desígnios constitucionais. No entanto, é necessária uma conscientização da população que deve exigir e fiscalizar as políticas públicas que asseguram uma efetiva proteção ambiental, pois incontáveis são os danos decorrentes da ausência da elaboração e implementação de políticas públicas na área ambiental.

Embora as políticas públicas configurem-se como atos do Estado junto a sociedade, é importante a possibilidade de uma efetiva participação popular, uma vez que várias 
políticas são implantadas em resposta às demandas que emergem da sociedade. As questões ambientais são demandas sociais com uma relação direta com as políticas públicas, portanto, a contextualização com relação aos interesses da sociedade torna-se primordial. Nesse sentido, a avaliação das políticas públicas possibilita uma reflexão sobre o desenvolvimento sustentável que está sendo conseguido com a mensuração das consequências da efetiva implantação dessas políticas. A avaliação possibilita, ainda, compreender os benefícios sobre a população e o desenvolvimento pretendido, considerando os desafios, as possibilidades e os meios necessários para execução desse tipo de desenvolvimento.

A doutrina jurídico-ambiental brasileira possui um posicionamento comum no que diz respeito à proteção do meio ambiente. Este posicionamento se tornou mais perceptível quando da promulgação da Lei no 6.938/81 e da Lei no 7.347/85. A Lei no 6.938/81 dispõe sobre a Política Nacional do Meio Ambiente (PNMA), seus fins e mecanismos de formulação e aplicação, tendo por objetivo a preservação, melhoria e recuperação da qualidade ambiental propícia à vida, visando assegurar, no país, condições favoráveis ao desenvolvimento, aos interesses da segurança nacional e à proteção da dignidade da vida humana. Já a Lei no 7.347/85 disciplina a ação civil pública de responsabilidade por danos causados ao meio ambiente. Tais leis dispuseram diretrizes voltadas à defesa ambiental no país, que contribuíram na formulação da Constituição Federal de 1988.

As transformações da sociedade têm forçado o Estado a uma mudança nos modelos de gestão ambiental. Modelos apoiados em vários instrumentos (plano diretor, estatuto das cidades, planejamento participativo e audiências públicas) e no suporte da sociedade civil organizada têm aprimorado as políticas públicas ambientais. Os modelos de gestão ambiental consistem em um conjunto de medidas e procedimentos bem definidos que, quando adequadamente aplicados, permitem reduzir e controlar os impactos negativos sobre o meio ambiente, além de contribuir para a melhoria contínua das condições ambientais em equilíbrio com a sociedade. O enfoque em melhoria contínua dos modelos de gestão ambiental preconiza uma revisão constante de cada passo visando a implementação de novas técnicas de gerenciamento ambiental. Assim, deve-se desenvolver um 
planejamento que englobe os objetivos, as metas e os programas ambientais, sempre realizando uma análise crítica.

Mesmo com o aprimoramento da legislação ambiental brasileira, o grande número de leis e a complexidade da temática não têm sido suficientes para garantir uma melhoria na qualidade ambiental. $\mathrm{O}$ fato de a legislação ambiental brasileira ter sido elaborada de modo autocrático, sem a socialização do conhecimento, gera conflitos e dificulta a execução de políticas públicas ambientais convergentes. Outra problemática ligada à legislação ambiental brasileira deve-se ao fato de normas e regulamentações serem linearmente padronizadas, pressupondo um espaço homogêneo quando na realidade existem espaços ecológicos distintos e uma grande pressão agrícola, no que diz respeito ao avanço do agronegócio na fronteira de expansão agropecuária.

Conforme o exposto, se traduz como objetivo deste trabalho analisar as políticas públicas ambientais no Brasil, abordando assuntos relativos a conceituação, análise histórica, breve explanação sobre a influência das políticas internacionais e no âmbito local, por fim, culminando em uma compreensão dos aspectos críticos acerca dessa temática.

A metodologia utilizada foi uma revisão bibliográfica e documental sobre o tema, buscando inserir uma visão crítica sobre a problemática das políticas públicas ambientais no Brasil.

\section{Conceituação de políticas públicas ambientais brasileiras}

Segundo Souza (2003), o crescente interesse pela temática das políticas públicas, em especial relacionados aos países da América Latina, ocorreu devido a impossibilidade de equacionar, ainda que minimamente, a promoção de diretrizes nessa área de atuação capaz de impulsionar o desenvolvimento econômico, aliado à inclusão social de grande parte da população. No Brasil, este debate somente foi impulsionado e passou a fazer parte da agenda de pesquisa nas últimas décadas, dentre outros motivos, pela formalização de grupos temáticos em algumas associações científicas.

Para Sorrentino et al. (2005, p. 290), "uma política pública representa a organização da ação do Estado para a solução de um problema ou atendimento de uma demanda específica da sociedade". De forma que se pressupõe que as políticas, no estado de direito 
democrático, dependem de muitos fatores e de diferentes momentos históricos de cada país.

Em se tratando especificamente das políticas públicas ambientais, Fernandez-Vítora et al. (1996) as conceitua como sendo um conjunto de atividades e procedimentos executados pelos diferentes níveis de competências e organizações do Estado além de incluir empresas e organizações não-governamentais que intentam alcançar fins específicos de proteção e conservação do meio ambiente.

Em complemento ao pensamento de Fernandez-Vítora et al. (1996), Floriano (2007) afirma que as políticas públicas ambientais devem ir além da gestão de recursos para proteger o ambiente natural. Ou seja, é necessário que tais normativas sirvam principalmente para orientar e trazer soluções para quaisquer conflitos sociais que tratem de questões ambientais, buscando, com isto, favorecer o bem estar social e a conservação dos recursos para as gerações futuras.

Embora haja explicações distintas a respeito das causas que, em cada sociedade, alavancaram um aumento no interesse em relação à qualidade do meio ambiente, Fuks (1998) aponta que isto se deve, basicamente, a ampla difusão, em dimensão global, das preocupações com assuntos ligados ao meio ambiente.

Do exposto, depreende-se que no Brasil os assuntos relativos às políticas públicas ambientais foram incentivadas por um amplo escopo que incluem um conjunto de variáveis que perpassam a simples busca pela proteção ao meio ambiente. Estas estão relacionadas à construção de associações científicas nesta área, ao aumento das discussões sobre a temática em nível internacional e se devem, também, à busca, ainda que de forma bastante incipiente, pela qualidade de vida do agente social e de seu equilíbrio com o meio ambiente.

\section{A influência das políticas internacionais de gestão ambiental}

Nunes et al. (2012) relatam que as primeiras discussões internacionais em relação aos problemas ambientais se referem a assuntos pontuais e de interesse comum entre alguns países. Isso ocorreu de forma que os debates relacionados com assuntos ambientais no âmbito internacional se tornaram mais abrangentes e disseminados, dentre outras 
iniciativas, a partir da Conferência de Estocolmo, na década de 1970, pela divulgação do Relatório Brundtland, nos anos de 1980, e pela realização da Rio 92, na década de 1990.

Na perspectiva de Floriano (2007), as políticas internacionais de gestão ambiental têm sido apresentadas sobretudo durante as mais variadas conferências das Nações Unidas relacionadas à área ambiental. Cita-se, por exemplo, a Agenda 21, instrumento que trata a respeito de políticas ambientais e de desenvolvimento, a nível mundial. Além disso, tal desenvolvimento traz recomendações que visam reverter os efeitos da degradação ambiental no planeta, sugerindo que a mesma seja adotada também no âmbito local. Tal documento foi criado em meio à Conferência das Nações Unidas sobre Ambiente e Desenvolvimento, realizada em 1992 no Rio de Janeiro, também chamada de ECO-92.

Apesar de a Agenda 21 representar um avanço por convocar a sociedade civil para o debate e a construção de um desenvolvimento sustentável, esse avanço se esbarra com as forças vigentes no mercado. Sendo assim, a ideia de consenso como condição fundamental para tornar o desenvolvimento sustentável possível resulta, na verdade, em um conflito pela exclusão da sociedade do desenvolvimento das políticas públicas ambientais. Portanto, todas as premissas da Agenda 21 direcionam para um modelo de desenvolvimento sustentável que para ser posto em prática, depende da quebra de certos paradigmas do capitalismo contemporâneo.

Faz-se menção também a outro documento relevante que foi emitido na mesma conferência, conhecido como a Declaração do Rio sobre Ambiente e Desenvolvimento. Neste são expostos 27 princípios em vista à proteção da integridade dos sistemas ambientais globais, além de contribuir para o desenvolvimento humano de maneira sustentável. Tais documentos, além de exercerem influência no cenário internacional foram essenciais, ao mesmo tempo, para a formulação de políticas ambientais brasileiras (FLORIANO, 2007).

Theodoro et al. (2004) enfatiza que parte da sociedade nacional teve uma participação ímpar na formalização de políticas nacionais ambientais. De forma que esta, por meio das pressões realizadas contra os governos e tomadores de decisão, conseguiu a aprovação de leis, normas e diretrizes que minimizassem ou até mesmo impedissem a execução de projetos prejudiciais ao meio ambiente e, consequentemente, à saúde humana. 
Em se tratando da gestão ambiental internacional, esta se baseia principalmente nos princípios da Declaração do Rio, na Agenda 21 e nos preceitos acordados por organizações internacionais como a ONU, a ISO e a OMC. Cita-se ainda o papel influente de órgãos financeiros internacionais nesse processo, como o Banco Mundial e o Banco Interamericano de Desenvolvimento. Os organismos financeiros internacionais usam do poder econômico para impor o cumprimento de princípios e normas ambientais internacionais na análise de projetos de desenvolvimento por eles financiados; influenciando o governo a se posicionar oficialmente sobre um processo de conscientização da sociedade sobre os problemas ambientais (FLORIANO, 2007).

\section{Histórico das políticas públicas ambientais brasileiras}

As questões e problemas relativos ao meio ambiente não são algo novo, nem uma necessidade nova que agora surge para ser atendida. A humanidade sempre teve que interagir com o meio ambiente, enfrentando as consequências quando essa interação não ocorreu de maneira responsável (SPERANDIO; GASPAR, 2009). A política ambiental brasileira tem um histórico de leis que representam marcos regulatórios importantes para a proteção dos recursos naturais.

Conforme Magrini (2001), a política ambiental brasileira, desde suas primeiras formulações, tem se mostrado atuante tanto no plano corretivo como no preventivo. Nunes et al. (2012) apontam que, no Brasil, desde a década de 1930, são criadas políticas regulatórias destinadas à proteção da natureza e de seus recursos. Exemplo disso é que em se tratando da esfera federal, no ano de 1934 foram criados o Código Florestal e o Código das Águas e das Minas. Já nas décadas de 1950 e 1960 foram desenvolvidas unidades de conservação, sendo a maioria destinadas à mata atlântica, bem como se instituiu a Lei do novo Código Florestal de 1965 e a Lei da Fauna, de 1967.

No âmbito nacional, essas preocupações com as políticas públicas de cunho ambiental tiveram maior importância a partir da década de 1970 , momento em que as Nações Unidas inseriram o tema nas agendas dos governos e o Brasil, então, passou por uma fase de reestruturação na área ambiental, especialmente no âmbito institucional. De forma que após a Conferência de Estocolmo, em 1972, foi criada, em 1973, a Secretaria Especial de 
Meio Ambiente (SEMA), uma instituição ligada à Presidência da República com o intuito de lidar especificamente com as questões ambientais (SORRENTINO et al., 2005; AZEVEDO et al., 2011).

Segundo Magrini (2001), mesmo com a existência de alguns instrumentos de gestão ambiental implementados nos anos 70, e embora a própria federação detivesse certas normativas desenvolvidas anteriormente (Código de Águas de 1934, a Lei de Proteção de Florestas de 1965, a Lei de Proteção da Fauna de 1967, dentre outras), considera-se que só foi implantada no Brasil uma política ambiental efetiva e orgânica em 1981, com a formalização da Lei no 6.938/81, responsável pela promulgação da Política Nacional de Meio Ambiente (PNMA).

Cavalcanti (2004) complementa esta argumentação defendendo que a Lei no 6.938/81, que posteriormente foi alterada pela Lei $10.165 / 00$, é a iniciativa mais significativa, até hoje, em se tratando da legislação ambiental brasileira. Esta abrangeu tanto a base legal como também incorporou o arcabouço institucional, objetivando, com isso, viabilizar políticas voltadas às questões ambientais em todos os níveis de governo (União, Estados e Municípios).

Azevedo et al. (2011) relatam ainda que a PNMA de 1981 foi importante por dois pontos fundamentais: descentralização da gestão e participação social institucionalizada. Nesse sentido, aborda-se que a Lei $10.165 / 00$ busca a preservação, melhoramento e recuperação da qualidade ambiental propícia à vida, além de intentar assegurar condições de desenvolvimento socioeconômico ao país. Esta, concomitantemente, estabelece os padrões de qualidade ambiental, zoneamento e avaliação de impactos ambientais; bem como inclui a criação de reservas e estações ecológicas, dentre outras providências (THEODORO et al., 2004).

Foi também por meio dessa lei que foi criado o chamado Sistema Nacional do Meio Ambiente (SISNAMA), que define parâmetros de gestão da coisa pública para deliberar sobre normas, padrões e regulamentos ambientais, cuja estrutura é composta por seu órgão superior, o Conselho de Governo, sob coordenação da Casa Civil. Já a instância deliberativa e consultiva do SISNAMA compete ao Conselho Nacional do Meio Ambiente (CONAMA) no qual uma de suas atribuições é propor diretrizes de políticas governamentais para o meio 
ambiente e para os recursos naturais (JABOBI, 2003). Na concepção de Jacobi (2003), a criação do SISNAMA e do CONAMA fez com que se incentivasse a participação da sociedade civil nas atividades de proteção ambiental.

Vale ressaltar, ainda, que tanto a Lei dos Interesses Difusos (Lei 7.347/85), como a Constituição Federal de 1988 representaram marcos que aumentam a democratização da política ambiental brasileira. Além disso, a Carta Magna trouxe vários avanços na área como um capítulo exclusivo sobre o meio ambiente. Esta também elevou os municípios à categoria de unidades federativas e estabeleceu princípios básicos para a repartição de competências entre os entes federados (AZEVEDO et al., 2011).

Observa-se que durante a década de 1990 houve um grande avanço legislativo na área ambiental como a aprovação de várias leis setoriais. Destaque para a Lei Nacional de Política de Recursos Hídricos (1997), a de Crimes Ambientais (1998), e a da Política Nacional de Educação Ambiental (1999) (BOEIRA, 2003).

Ainda na década de 1990, existiu uma maior ação de Organizações não Governamentais (ONGs) e movimentos ambientalistas que se tornaram mais participativos na formatação das políticas públicas. Além do envolvimento da sociedade local nas questões ambientais que passou a ser incentivado, os municípios tornaram-se mais autônomos. Alude-se também que o papel dos diferentes atores sociais na reformulação das políticas públicas passou a ser mais debatido. No entanto, o Estado continuou a formular e implantar políticas antagônicas, ditando tanto normas de proteção ambiental quanto estabelecendo leis contraditórias de incentivos fiscais e anistias que resultaram na aceleração da exploração florestal e da devastação dos recursos naturais (REANI, 2012).

Em compensação, em 1997 foi promulgada a regulamentação federal referente ao Licenciamento Ambiental (Resolução CONAMA 237/97), estabelecido pela PNMA, que fortificou os mecanismos regulatórios e flexibilizou as práticas até então vigentes.

Reani (2012) ressalva que de 1988 até os dias atuais, as políticas públicas ambientais foram marcadas pelo processo de redemocratização e pela promulgação de uma nova Constituição com forte tendência descentralizadora.

Em contrapartida a tal pensamento, Aguiar (2011) aduz que mesmo com a incorporação dos instrumentos protecionistas dos recursos naturais sendo considerado um 
avanço significativo na questão ambiental, a implementação desses dispositivos se concretiza de forma precária. Isto ocorre porque, na prática, tais instrumentos protecionistas são mal aproveitados e não se traduzem em conservação do meio ambiente e qualidade ambiental, servindo apenas aos discursos dos grupos de interesses contrários, que os consideram como um ônus ao desenvolvimento, pela impossibilidade de exploração de hectares destinados à conservação in situ da biodiversidade.

\section{Neo-extrativismo brasileiro}

Picoli (2011) relata que o avanço da exploração de commodities de exportação desencadeou impactos ambientais profundos. Esses impactos territoriais estão relacionados a três elementos: (a) o deslocamento de grande contingente de técnicos e operadores para as áreas de exploração florestal; (b) a ocupação de áreas indígenas e comunidades rurais; (c) a abertura de corredores de transporte e energia. Todos esses impactos foram desenvolvidos, orientados ou protegidos pelo Estado. Em muitos casos, esses impactos representaram um processo de desfragmentação geográfica, sobretudo na região amazônica, pela limitação na cobertura de direitos do cidadão. O Estado, então, se apresenta fraco ou ausente em muitas dessas áreas, mas garante apoio e proteção para as atividades extrativistas implantadas.

Os governos progressistas têm valorizado as exportações de commodities e o aumento apresentado tem significado um sucesso que justifica a intensificação de ações neste sentido. Vários países em desenvolvimento, em especial na América Latina, têm tomado esta medida como estratégia contra as restrições econômicas decorrentes de crises. Por isso, as metas de exportação de commodities têm se tornado um elemento chave na promoção do extrativismo. O sucesso das exportações de commodities e a busca por investimento estrangeiro figuram como os dois pilares das estratégias econômicas do progressismo.

Enquanto o velho extrativismo apontava para necessidade de exportação e para necessidade de atendimento ao mercado mundial, o discurso dos governos progressistas tem justificado as exportações na globalização e na necessidade de serem mais 
competitivos. A mudança não reduz o extrativismo, apenas torna-o contemporâneo e passa a envolver um conjunto mais amplo e complexo de comércio internacional.

O avanço da mineração, da exploração do petróleo e da monocultura de commodities para exportação representa a chegada de contingentes de operadores e técnicos com suas equipes e uma ligação logística formada por corredores de transporte e energia ligando a portos de exportação. Essas mudanças têm sido o centro de conflitos por conta dos impactos territoriais econômicos, sociais e ambientais gerados. Esses enclaves variam em função das desigualdades locais e dos casos de contaminação e de perda da biodiversidade.

O termo (neo)extrativismo usado por Eduardo Gudynas (2012) refere-se à exploração excessiva tanto dos recursos esgotáveis como, também, dos recursos renováveis. Portanto, evoluir no extrativismo significa uma transição para uma economia sustentável baseada na energia e materiais renováveis. As chamadas reservas extrativistas foram criadas como forma de mitigar o desmatamento na Amazônia, haja vista que a conversão da floresta em pastagens para o gado aumentava consideravelmente. Com isso, os seringueiros encontraram no termo reserva extrativista um significado legal por denotar áreas onde poderiam ser extraídas o látex das seringueiras e a castanha do Brasil de maneira sustentável e com a venda destinada a habitantes locais. Atualmente, pelo fato de as florestas assumirem outras funções ecológicas como a reciclagem da água e a absorção do carbono, as reservas extrativistas se fortaleceram como estratégia extrativista sustentável.

A transição gradativa da indústria de transformação de madeiras para a agropecuária de mercado é consequência do processo migratório e do avanço do agronegócio das monoculturas voltadas para o mercado internacional. Assim, surge um cenário regional que desencadeia duas importantes etapas produtivas regionais que se identificam com épocas e espaços cronologicamente diferenciados, expressando as formas de produção que caracterizam as grandes áreas de produção agrícola de exportação. Com essas características, essas grandes regiões agrícolas se consolidam como um espaço para que grupos econômicos se estabeleçam de modo a explorar os recursos naturais florestais e minerais abundantes. 
A organização desses espaços de exploração foi realizada através de uma articulação entre o poder público e o capital, tendo sido facilitada a aquisição de grandes áreas com o propósito de agregação de valor em grande escala através dos lucros advindos do processo de transformação de madeiras.

Esta estratégia desqualificou a maior parte das árvores, bem como não considerou alternativas da biomassa, tais como, resinas, tinturas, fibras, óleos, fitoterápicos, energias, sementes e frutos. Além do não aproveitamento de maneira sustentável das madeiras pela indústria de transformação, provocaram um desastre ambiental na maior parte dos espaços de intervenção. Todo processo de ocupação dessas terras se sustentou, em parte, pela grilagem de terras em articulação com parte das instâncias do aparelho de Estado brasileiro, conivente com essas irregularidades. Em decorrência, a possibilidade de um projeto voltado para áreas de madeiras com possibilidade de se converter em uma opção econômica e social, além de ambiental, para a região foi inviabilizado (PICOLI, 2011).

Toda essa transformação entregou para o agronegócio uma grande área propícia para produção de grãos e carne, produtos de exportação altamente competitivos e lucrativos. Atributos muito mais vantajosos que a indústria de transformação de madeiras, o que resultou em grandes mudanças na economia regional saindo de um modelo extrativista para um agronegócio estruturado e voltado para exportação.

Contudo, o poder público não foi o único responsável por esta nova configuração regional. As elites regionais, representadas pelos atores políticos, também, de forma articulada, realizaram estratégias com o capital local. Além disso, a mídia corporativa contribuiu decisivamente na construção de consenso de que o capital é a grande força regional.

\section{Políticas públicas ambientais brasileiras}

Como retrata Vallejo (2009) em relação à questão ambiental no Brasil, historicamente, é perceptível que sempre existiu um grande afastamento entre as políticas públicas de desenvolvimento econômico e as de proteção ambiental, e isto acarreta na forte deterioração dos ecossistemas do território nacional. Vallejo (2009) pondera, ainda, que, historicamente, as políticas públicas têm ignorado o valor agregado à manutenção do 
equilíbrio dos ecossistemas, privilegiando, em contrapartida, apenas os valores diretos e imediatos que são passíveis de obtenção a partir de sua exploração. Isto sugere que essas políticas ambientais, mesmo com os seus avanços, continuam sendo iniciativas que não garantem a sua plena aplicação, nem mesmo o alcance de seus fins.

Exemplo disso é que desde o período colonial, as políticas públicas no Brasil beneficiavam as atividades do extrativismo predatório, e que apenas ofertavam a possibilidade de preservação para espécies economicamente rentáveis. De forma que "os mecanismos de gestão associados com essas leis eram extremamente precários, prevalecendo o interesse privado em detrimento do público" (VALLEJO, 2009, p. 78). Na visão do autor, as tentativas de reformulação do modelo político, entre meio ambiente e sociedade (sendo considerada altamente segregada) ocorreram na década de 1980, com a concepção e implantação da Política Nacional do Meio Ambiente (PNMA). No entanto, nos anos 80, após a criação do PNMA, a chamada crise do Estado Desenvolvimentista prejudicou o funcionamento de um novo arranjo político-institucional e reduziu a abertura de agências governamentais interessadas na área ambiental (VALLEJO, 2009).

Em se tratando da PNMA (1981), essa não foi capaz de se construir ou se estruturar plenamente devido às dificuldades inerentes à complexa articulação política nesse setor, bem como pela falta de capacidade institucional e de recursos humanos que viabilizassem a devida aplicação da lei. E isto culminou na desestabilização do sistema ambiental nacional, de tal maneira que essa situação permaneceu até o início da década de 2000. Ainda assim, vários estados brasileiros vêm buscando superar as lacunas do poder criadas pelo novo ordenamento legal brasileiro referente ao PNMA. Portanto, a construção de políticas ambientais, em parte, são o resultado de uma série de conflitos de competências não solucionados, bem como, reflexos da própria ambiguidade da constituição brasileira no tocante à distribuição de competências na área ambiental (VILLARROEL, 2012).

Tal dificuldade também recai na gestão das políticas públicas ambientais, uma vez que este sistema é ineficiente e se caracteriza por diversos conflitos de ação institucional. Cita-se como modelo disso a atual desarticulação entre o poder público de esferas distintas, ou até mesmo dentro de um próprio ente político. Isto reafirma que o federalismo 
cooperativo não é aplicado, já que ou todos se omitem, ou todos querem licenciar e aplicar sanções (CAPELLI, 2002).

Nunes et al. (2012) tocam num ponto fundamental, de que mesmo que as leis ambientais brasileiras sejam consideradas bastante avançadas e bem elaboradas, estas justamente se confrontam com a lacuna em sua aplicação, o que acarreta na inviabilidade de sua efetiva implementação. Como exemplo, cita-se as contemporâneas, complexas e polêmicas discussões que giraram em torno das alterações no Código Florestal Brasileiro.

A esse respeito, Abreu (2012) mostra que há uma desconexão entre o discurso e a prática no novo Código Florestal, pois anula a aplicabilidade de um relevante conjunto de leis ambientais para ofertar ainda mais espaço para o agronegócio e o setor imobiliário, abrindo possibilidades de lucros cada vez maiores para os atores sociais ligados ao meio empresarial, podendo ocasionar danos irreparáveis ao meio ambiente e ao patrimônio cultural. Mostrando assim, uma incompatibilidade com o objetivo da Rio+20 de assegurar um comprometimento político renovado com o desenvolvimento sustentável.

Outro grande problema, como aponta Lopes (2006), é que, no Brasil, as políticas públicas e comandos estatais relacionadas às causas do meio ambiente costumam deter baixa eficiência e serem bastante fragmentadas e setorizadas. De maneira que quando não há compromisso e colaboração individual e cívica com as questões ambientais, isto incita e legitima a participação popular na área e tende, portanto, à maior democratização das políticas públicas.

Dito isto, é verificado que as políticas públicas ambientais são elaboradas guiandose por uma política nacional e pelos instrumentos contidos no Estatuto da Cidade, no Plano Diretor e no zoneamento urbano. Dessa forma, a atuação de ONGs, dos Conselhos Municipais e da sociedade civil organizada nas audiências públicas se tornam cada vez mais presentes no planejamento participativo e na preservação do meio ambiente no espaço urbano. Se colocando assim como uma renovação, um novo caminho para o planejamento urbano no Brasil, mesmo que, em muitos casos, isto se reflita apenas como uma ação consultiva (REANI, 2012).

Nesse sentido, a própria Constituição de 1988 e a atual configuração estatal estimulam políticas públicas e favorecem uma maior participação popular, na qual essa seria 
uma nova forma de gerir a coisa pública. No entanto, nem sempre tais formas e instrumentos participativos propostos pelas políticas democráticas sabem lidar com as demandas populacionais ou ao menos representam os interesses dos mesmos (LOPES, 2006).

Por outro lado, na perspectiva de Layrargues (2002), os movimentos sociais, que ocorrem medidas por formas coletivas de reivindicação e por instâncias institucionalizadas (sobretudo aqueles voltados aos movimentos ambientalistas dos órgãos colegiados consultivos ou deliberativos), são necessários para que a implementação de políticas públicas do interesse dos indivíduos seja, de fato, garantida.

Tais problemas têm beneficiado, principalmente, o fortalecimento do setor privado, que tem por característica a organização orientada pela maximização dos lucros. Essa situação faz com que o Estado e a sociedade civil se tornem reféns de decisões implementadas à sua revelia e, além disso, permite que a figura governamental vire apenas um mero mitigador de impactos previamente engendrados (CAPELLI, 2002). Não se pode esquecer, contudo, que não só as firmas são responsáveis pelos danos ambientais, mas o próprio Estado, por meio de sua atuação efetiva, contribui para a degradação da natureza.

Por fim, se verifica que é necessário que haja uma maior integração entre políticas públicas ambientais, bem como é essencial que sejam redefinidos os papéis do Estado, empresas, ONGs e sociedade civil neste processo que engloba modelos de planejamento participativos. Se busca, com isso, garantir o devido cumprimento das regulamentações em favor das causas ligadas ao meio ambiente.

Diante do exposto, o que pode ser visto neste trabalho é que as políticas ambientais governamentais foram organizadas sob interesses diversos e, muitas vezes, desarticuladas dos interesses da sociedade. Esse desarticulação gerou, ao longo dos anos, conflitos ambientais oriundos da exploração intensiva do ambiente com culturas agrícolas de exportação subservientes aos circuitos de negociação internacionais sem preocupação maior com a sustentabilidade. Com isso, muitos conflitos e contradições foram alimentando as relações entre o moderno agronegócio capitalista, o governo e a sociedade, justamente pela contradição das políticas ambientais em defesa do meio ambiente e a degradação deste por interesses econômicos. Tudo seguindo uma racionalidade econômica que explora 
demasiadamente os recursos naturais sem uma preocupação social e promovendo a destruição da biodiversidade e das identidades locais.

Portanto, analisar as políticas ambientais e toda a problemática envolta pode representar uma significativa contribuição a uma nova percepção das dimensões da sustentabilidade (econômica, social e ambiental) nos processos de conscientização e construção de um modelo de desenvolvimento que reconheça a potencialidade dos recursos naturais e a necessidade de melhoria da qualidade de vida das populações e não somente o potencial de geração de riqueza.

\section{Conclusão}

Nos últimos anos, identifica-se que o aparato legal disponível na legislação ambiental brasileira tem sido uma poderosa ferramenta de transformação da sociedade e está trazendo um debate no que concerne às questões sobre o uso dos recursos naturais, uma vez que este provoca reflexões acerca das limitações, deveres e direitos dos cidadãos em relação ao meio ambiente (THEODORO et al., 2004).

Além disso, esta abrange tanto procedimentos metodológicos, jurídicos, econômicos ou sociais capazes de transformar o relacionamento entre a sociedade e a natureza, tornando-a mais harmônica e gerando, consequentemente, uma nova e melhor forma de administrar o uso dos recursos naturais.

Com a maior propagação do assunto em nível mundial, e pela sua formalização em debates, eventos e palestras, a sequência histórica da implementação de leis, decretos e normas no Brasil demonstram que em face à pressão normativa e social, tal aparato regulamentário criou mecanismos para tratar os principais problemas ambientais, ainda que tenham ocorrido de forma lenta, mesmo que progressiva.

Este progresso tornou-se mais perceptível especialmente após a implementação da Lei 9.638/81, alterada pela Lei 10.165/00, visto que esse instrumento legal está disciplinando as formas para que o planejamento e implantação dos projetos ambientais com teor preservacionista sejam aplicados. Isto significa que estes mecanismos, por um lado, favorecem a condução dos processos de gestão ambiental de forma mais integrada, viabilizando uma série de conquistas. Por outro lado, a aplicação deste aparato, unicamente, 
não foi capaz de resolver certos conflitos gerados pelo uso dos recursos ambientais por diferentes atores sociais, aprofundando com isso ainda mais os impasses de natureza socioambiental.

Percebe-se com isto que as políticas nacionais nada mais são do que o reflexo de uma dependência de diretrizes primordialmente internacionais, uma vez que no Brasil não se identifica um maior comprometimento na luta por causas ambientais, caso não haja, em contrapartida, uma respectiva obrigatoriedade ou normativa que imponha o cumprimento de certas medidas protecionistas. Isto sugere que o interesse econômico, em se tratando de sua natureza com viés exploratório, prevalece sobre o interesse de uma minoria que almeja e luta por um mundo mais sustentável.

Neste sentido, as políticas públicas ambientais devem estabelecer uma relação em que o sistema político não privilegie o mercado em detrimento de uma sociedade que valoriza sua cultura e a socialização de suas identidades. Portanto, a dualidade existente entre o meio ambiente e o mercado não pode afetar ou ignorar uma sociedade que está inserida e que tem como direito analisar o controle dos recursos naturais e a interferência sobre o desenvolvimento sustentável.

Por esta razão se faz necessário que primordialmente haja um fortalecimento do Estado perante tamanhas inconsistências práticas e políticas de sua própria instituição, que em muitas casos apresentam posicionamentos igualmente controversos na qual, por um lado, defendem a causa em proteção ao meio ambiente e, por outro, se mostram coniventes e de certa forma até estimulados por interesses diversos, a aceitar práticas irregulares e extrativistas pelo setor privado. O que sugere que deve existir uma maior fiscalização e cumprimento das normas perante todos os entes, independente de qual sejam seus respectivos papéis sociais.

Intenta-se com isto demonstrar que tais ideias de modelos preservacionistas socioambientais precisam ser mais incisivas no que se refere ao seu devido embasamento, efetivação, cumprimento e fiscalização. Embora algumas políticas públicas voltadas a esta área detenham orientação e aplicação, essas claramente não possuem capacidade, por si só, para enfrentar os desafios de modo operante ao cumprimento de um desenvolvimento plenamente sustentável. Se reconhece portanto que as limitações e desafios para uma real 
preservação dos recursos naturais, uma vez que este é um assunto complexo e dinâmico que envolve diversos setores e respectivos grupos de ação.

Conclui-se, portanto, que em se tratando dos mecanismos próprios de gestão das políticas públicas, estes tanto podem contribuir para que os problemas ambientais sejam minimizados, ou, em certos casos, podem abrir precedentes capazes de gerar e agravar ademais conflitos socioambientais.

As limitações encontradas referem-se à reduzida quantidade de referencial teórico que tragam discussões sobre os conflitos existentes em decorrência das políticas públicas ambientais. Por este motivo, as recomendações deste trabalho são de que novos trabalhos sejam desenvolvidos a partir de olhares críticos para cada conflito ambiental identificado, no sentido de ter-se uma contribuição política, ideológica e social nas discussões e na efetiva aplicação de novas políticas públicas ambientais.

\section{Referências}

ABREU, M. S. de Código Florestal Brasileiro e Código Ambiental de Santa Catarina: legislação a favor do lucro. Revista Brasileira de Estudos Latino-Americanos - REBELA, Florianópolis, v.2, n.1, p.471-480, set./dez., 2012.

AGUIAR, C. D. Sobreposições entre Políticas Públicas: obras do PAC e unidades de conservação no corredor de biodiversidade da Serra do Mar. 110p. Dissertação (Mestrado em Desenvolvimento Sustentável) - Universidade de Brasília, Brasília, 2011.

AZEVEDO, A.; PASQUIS, R.; BURSZTYN, M. A reforma do Estado, a emergência da descentralização e as políticas ambientais. Revista do Serviço Público, Brasília, v.58, n.1, p.37-55, jan./mar., 2007.

BOEIRA, S. L. Política e gestão ambiental no Brasil: da Rio-92 ao estatuto da cidade. Revista Alcance, Biguaçu, v.10, n.3, p.525-558, 2003.

CAPELLI, S. Gestão ambiental no Brasil: sistema nacional de meio ambiente-do formal à realidade. In: Conferencia Internacional sobre aplicación y cumplimiento de la Normativa Ambiental en America Latina - FARNC, Buenos Aires, Argentina. Tópico temático: Aspectos Institucionales, coordinación interjurisdiccional y organizacion administrativa, mai., p.49-57, 2002. 
CAVALCANTI, C. Economia e ecologia: problemas da governança ambiental no Brasil. In: Revista de la Red Iberoamericana de Economia Ecológica - Revibec, v.1, p.1-10, 2004.

FERNÁNDEZ-VÍTORA, V. C.; RIPOLL, V. C.; RIPOLL, L. C. Los instrumentos de la gestión ambiental en la empresa. Mundi Prensa Libros SA, 1996.

FLORIANO, E. P. Políticas de gestão ambiental. 3. ed. Santa Maria. Universidade Federal de Santa Maria. Departamento de Ciências Florestais, p.128, 2007.

FUKS, M. Arenas de ação e debate públicos: conflitos ambientais e a emergência do meio ambiente enquanto problema social no Rio de Janeiro. Dados, v.41, n.1, p.230-245, 1998.

GUDYNAS, E. Diez tesis urgentes sobre el nuevo extractivismo. Extractivismo, política y sociedad, p.187-225, 2009.

JACOBI, P. R. Espaços públicos e práticas participativas na gestão do meio ambiente no Brasil. Sociedade e Estado, Brasília, v.18, n.1-2, p.315-338, jan./dec., 2003.

LAYRARGUES, P. P. Educação para a gestão ambiental: a cidadania no enfrentamento político dos conflitos socioambientais. In: LOUREIRO, C. F. B.; LAYRARGUES, P. P.; CASTRO, R. S. (Org). Sociedade e meio ambiente: a educação ambiental em debate. 3. ed. São Paulo: Cortez, p.87-155, 2002.

LOPES, J. S. L. Sobre processos de "ambientalização" dos conflitos e sobre dilemas da participação. Horizontes Antropológicos, Porto Alegre, v.12, n.25, p.31-64, jan./jun., 2006.

MAGRINI, A. Política e gestão ambiental: conceitos e instrumentos. Revista Brasileira de Energia, Rio de Janeiro, v.8, n.2, p.1-8, jun., 2001.

NUNES, M. R.; PHILIPPI JR., A.; FERNANDES, V. A Atuação de conselhos do meio ambiente na gestão ambiental local. Saúde e Sociedade, v.21, n.3, p.48-60, 2012.

PICOLI, F. Do Extrativismo ao agronegócio das monoculturas de mercado na Amazônia Norte Mato-Grossense. Revista Brasileira de Estudos Latino-Americanos - REBELA, v.1, n.2, 2011.

REANI, R. T. Organização do espaço e políticas públicas ambientais no município de São Jose dos Campos - SP. 287p. Tese (Doutorado em Geografia) - Curso Pós-Graduação em Geografia Humana, Faculdade de Filosofia, Letras e Ciências Humanas, Universidade de São Paulo, São Paulo, 2012.

SORRENTINO, M.; TRAJBER, R.; MENDONÇA, P.; FERRARO JÚNIOR, L. A. A. Educação ambiental como política pública. Educação e Pesquisa, São Paulo, v.31, n.2, p.285-299, mai./ago., 2005.

SOUZA, C. Políticas públicas: questões temáticas e de pesquisa. Caderno CRH, Salvador, v.16, 
n.39, p.11-24, jul./dez., 2003.

SPERANDIO, S. A.; GASPAR, M. A. Gestão socioambiental em empresas industriais. Revista de Administração de Empresas - UFSM, Santa Maria - RS, v.2, n.1, p.21-40, jan./abr., 2009.

THEODORO, S. H.; CORDEIRO, P. M. F.; BEKE, Z. Gestão ambiental: uma prática para mediar conflitos socioambientais. Associação Nacional de Pós-Graduação e Pesquisa em Ambiente e Sociedade - ANPPAS. ENCONTRO DA ASSOCIAÇÃO NACIONAL DE PÓS GRADUAÇÃO E PESQUISA EM AMBIENTE E SOCIEDADE. São Paulo, Anais... p.1-17, 2004.

VALLEJO, L. R. Unidade de Conservação: Uma Discussão Teórica à Luz dos Conceitos de Território e Políticas Públicas. Geographia, v.4, n.8, p.57-78, 2009.

VILLARROEL, L. C. L. A evolução da Política de Criação de Unidades de Conservação no Estado do Amazonas no período de 1995 a 2010. 161p. Dissertação (Mestrado em Desenvolvimento Sustentável) - Centro de Desenvolvimento Sustentável. Universidade de Brasília, Brasília, 2012. 